\title{
Cultural responsive teaching of language teachers in indigenous classrooms: A phenomenological inquiry
}

\author{
Aporbo, Russel
}

russel_aporbo@umindanao.edu.ph

Faculty-University of Mindanao Tagum College, Tagum City, Davao del Norte,8100, Philippines

\begin{abstract}
This phenomenological inquiry aimed to investigate the experiences of language teachers in indigenous classrooms of Pong-Pong Elementary School, New Bataan, Davao de Oro, Philippines. This also investigated the different coping mechanism of these challenges encountered in providing a cultural responsive teaching. The study utilized the purposive sampling technique which included seven (7) teachers for focus group discussion and for in-depth-interview; thematic analysis is used and themes were identified in this inquiry. In providing cultural responsive teaching experiences, themes revealed that teachers: use code-switching, linguistic contrast of teachers' and students' native language, challenges in the implementation of the curriculum, lowering the filter of anxiety level, and availability of language exercises in the target language. On the coping mechanism of teachers, themes are: use of student-centered strategies, immersion to students' diverse cultural backgrounds, making the classroom into a class-home, translation as a strategy and mastery of basic literacy skills
\end{abstract}

Keywords: Cultural responsive teaching; language teachers; indigenous classroom; and phenomenological inquiry

\section{Introduction}

To be contextually relevant, teachers should embrace students' diversity and provide authentic learning experiences in the classroom. Language classrooms, as melting pot of different worldviews, religious beliefs and values as well as students' linguistic origin, are recognized as a challenge yet an opportunity to explore.

As culturally responsive, teachers should build meaningful connections between the home and school experiences as well as between the academic abstractions and lived socio-cultural realities, use of instructional strategies that are suited to the students' learning styles, appreciate students cultural heritage and incorporate multicultural information and communicate all these to students in recognition of cross-cultural settings (Gay, 2010 as cited by Cabal 2017).

However, various researches also implicate that teachers, who do not have concrete backgrounds about indigenous communities, lack skills in providing cultural responsive teaching. In Australia, most of their teachers have inadequate knowledge on the appropriate pedagogies and complexities of indigenous cultures despite the commitments of educators to address the different needs of students (Australian Journal of Teacher Education, 2011). Many strategies that are considered useful and effective for non-indigenous learners are often irrelevant and ineffective for those indigenous learners who at the same considered as the most educationally disadvantaged group in the country (Australian Bureau of Statistics, 2007; Doyle and Hill, 2008) 
Knowing the challenges of ethnolinguistic and culturally diverse society, Philippines also shares the same struggles. Language teachers who are not indigenous really find it difficult in addressing the need of indigenous learners. Evidences contend the diverse causes of the students' failures in educating indigenous people which are similar in the studies conducted in different countries. Identified causes are lack of contextualization of the lessons, lack of integration of cultural values in classroom experiences, lack of bridge connection between school and the community, lack of understanding of the indigenous people's way of thinking and lack of learning support to indigenous children (Fiagoy, 2000 as cited by Cabal, 2017).

The Philippine's Department of Education empirically claimed that indigenous communities remain some of the most vulnerable and marginalized people (Rimando, 2013). Though this pressing situation has been the focus of the reformation of the curriculum for years, these efforts are not successful in improving the quality of lives of the indigenous community. In the far flung areas in the province of Davao de Oro, teachers struggle on their approaches of teaching to indigenous learners due to the linguistic barrier and cultural differences. Due to their first language, indigenous children have limited grasp of concepts presented. The contextualization and the localization of the learning materials added up the daily struggles of teachers who at the same time have limited knowledge on the societal challenges, norms and practices of indigenous children.

Serious deliberation should be undertaken by curriculum experts and stakeholders to address this mismatched implementation of the curriculum against its curriculum goals specifically in teaching language subjects to indigenous learners.

To date, few researches are available regarding the indigenous education in Davao de Oro and studies on the experiences of language teachers handling IP learners can rarely be found. Thus, it is in this premise that study on the experiences of language teachers in Davao de Oro should be conducted in order to investigate the different pedagogical and sound practices of language teachers in teaching indigenous learners which can contribute to the collections of studies that tackle the importance of cultural responsive teaching.

\subsection{Literature Review}

This study used the most renowned framework of Gay's Cultural Responsive Teaching which implicates the use of the cultural knowledge, prior experiences, frames of reference, and performance styles of ethnically diverse students to make learning encounter more relevant and effective for them." (Zeichner, 1993).

Culturally responsive instruction necessitates that language teachers should be knowledgeable about students' home cultures, language, and needs. Gay (2002) notes that today's classrooms require teachers to educate students varying in culture, language, abilities, and many other characteristics. She also argues (2000) that effective culturally responsive teachers consistently acknowledge the legitimacy of the cultural heritages of different ethnic groups, both as legacies that affect students' dispositions, attitudes, and approaches to learning and as worthy content to be taught in the formal curriculum.

Sarah Edwards (2011) also claimed the eight dispositions to make a culturally responsive teaching successful: culturally responsive educational materials and content; educators knowledgeable about all aspects of multicultural education; multi-culturally supportive learning environments; culturally responsive assessment batteries; on-going family and community communication and involvement; ethnically and culturally responsive curriculum; integration of cultural responsiveness throughout all academic areas and; personnel knowledgeable in culturally responsive behaviour management practices. 


\subsection{Research Questions}

This study sought to answer the following questions:

1. What are the experiences of language teachers in providing cultural responsive teaching in Indigenous classroom?

2. How do language teachers cope with the challenges in providing culturally responsive

\section{Method} teaching in Indigenous classrooms?

\subsection{Research Design}

This study utilized qualitative approach in which the process of inquiry flows from philosophical assumptions, to interpretive lens and on to the procedures involved in studying social or human problems. Data were collected by the researcher in a natural setting which are sensitive to people concerned and analysis of date includes inductive and deductive ways to establish the patterns of themes (Creswell, 2013).

Responses from the language teachers were recorded and transcribed to answer the research questions. Various challenges and struggles of language teachers handling indigenous learners were unfolded in order to elucidate cultural responsive teaching.

To specific, this study utilized phenomenological inquiry in which several individuals were studied as their lived experiences are considered as phenomenon. It focuses on describing a phenomenon that all the participants have experienced, such as learning a second language in a school system. The purpose of the phenomenological method is to "reduce individual experiences with a phenomenon to a description of the universal essence" and in order to achieve this goal, a researcher usually identify a phenomenon for study (Creswell, 2013).

\subsection{Sample/ Participants}

The participants of this phenomenological study were language teachers teaching IP students in Pong-Pong Elementary School, Davao de Oro, Philippines. Moreover in this study, these teachers have experiences on providing a cultural responsive teaching to indigenous learners. These participants were identified since they are deemed significant people who can assert their experiences in teaching IP students.

There were seven (7) teachers purposively selected as research participants of the study, who were subjected for IDI and for FGD. This number according to Creswell (2013) is enough to gather empirical data sources as bases for analysis and discussion. These were identified personally by the researcher through their school head. They were teachers who would be able to answer and share about their experiences specifically teaching IP students, how they build bridges in the implementation of the curriculum and how they broaden their perspectives in the teaching profession.

\subsection{Data Collection Procedure}

First, the researcher sought the permission from the DepEd Division supervisor of Davao de Oro and school head of Pong-Pong Elementary to conduct the inquiry regarding the phenomenon identified. 
Second the permission of the research participants were also sought to observe the actual class discussions and conduct the focus group discussion and in-depth interviews as data sources of the study.

Third, triangulations of data are followed to obtain the sources of the study. Triangulation means using more than one method to collect data on the same topic. Triangulation is used in order to map out and describe more concisely the intensity and complication of the problem. This method is the combination of methods used to produce more empirical materials for a more precise, thorough and objective representation of the study. Silverman (2007) added that the written document observed by the informants and the responses of interviews could be triangulated (Raagas, 2010).

In this study, data triangulation entails gathering data through several sampling strategies so that slices of data at different times and in different social situations, as well as on a variety of people, are gathered. One of the data sources for me to gather empirical data for analysis were classroom observations. Through the conduct of classroom observations, different practices in contextualizing the curriculum towards the students' needs were identified. Moreover, struggles and gaps between teachers and students will also be revealed upon the delivery of the curriculum.

To see the different perspectives of teachers, a Focus Group Discussion (FGD) was conducted to investigate about the practices of the participants in the actual curriculum implementation. Focus groups were used for generating information on collective views, and the meanings that lie behind those views. They are also useful in generating a rich understanding of participants' experiences and beliefs.

To gain quality, reliable and unbiased information, Raagas (2010) emphasize emphasized that through indepth interview, there are more in-depth, representation, efficacy, efficiency, and value. In this study, the nondirective in-depth interview was employed so that the informants were given maximum freedom to respond within the limits of the topic.

Fourth, the data collected were analyzed utilizing the Cultural Responsive Teaching Theory of Geneva Gay (2010). The researcher focused on the challenges experienced by the research informants and then, few examples were selected for elaboration.

Fifth, the results were stated in order to answer the question of the study. Generated explanations in the selected examples in the observations and interviews were provided in order to find out the challenges, coping mechanisms and insights of teachers handling IP students.

\subsection{Data Analysis}

Content and thematic analyses were employed by the researcher in which the data were grouped according to the themes and core ideas which existed during the conduct of the study. These identified themes and core ideas were interpreted and analyzed based on the objective of the study. Specifically, Creswell's (2013) steps in elaborating phenomenological analysis were employed. Each of the relevant quotes was listed on how language teachers provide a cultural responsive teaching in their Indigenous classroom. Relevant topics were grouped into units of meanings for thick description and identify the common element mentioned and experienced by all research participants. 


\section{Results}

In order to come up with the core ideas and themes of the study, the researcher only focused on the essential clauses and phrases emerged from the transcripts. These selected statements were grouped according to core ideas and were selected in order to determine patterns and connections between themes based on the objective of the study. Creswell's steps in elaborating phenomenological analysis were adopted.

\section{Experiences of Language Teachers in Providing a Cultural Responsive Teaching in IP Classrooms}

There were many essential themes emerged from the in-depth interview conducted. The answers of the research participants mainly focused on the cultural responsive practices in handling IP learners. The participants were asked to vividly describe their experiences to shed light on their lived experiences as teachers in the indigenous classroom.

After conducting the interviews with the research participants, thorough transcription and careful scrutiny were done in order to generate themes essential to address the research objectives Provided in Table 1 are the essential themes generated from the first research question.

Table 1: Themes and Core Ideas on Experiences of Language Teachers in Indigenous Classrooms

Major Themes

Use of code-switching in the classroom

\section{Core Ideas}

Teachers made use of literal translation and code switching from English to vernacular.

Lessons are explained in simpler terms.

Revise the content of the lesson into Mandaya language.

Teachers seeks the help of students who are competent in both English and native language.

More examples are given in the mother tongue.

\section{Linguistic Contrast of Teachers' and Students' Native language}

\author{
Challenges in the Implementation of \\ the Curriculum
}

\section{Lowering the Filter of Anxiety level}

\author{
Availability of language exercises in the \\ target language
}

Students' comprehension is low due to linguistic barrier Major adjustments to students' level of linguistic competence .

Difficulty to deliver the lesson due to language differences.

Pronunciation of words in target language is influenced by the students' mother tongue

Students answers are difficult to understand when they used their dialect.

Difficulty to follow the Curriculum Guide due to students' low-level of mastery.

Unable to explain the lesson well.

Unable to understand what the students want to express.

Let the students feel the sense of belongingness in teaching

Mix the IP students to Non-IP students.

Give necessary time and exposure to learn the language Read aloud and explain the literary piece. 
Table 2: Themes and Core Ideas on How Language Teachers cope with the Challenges in Providing a Cultural Responsive Teaching in Indigenous Classrooms

\begin{tabular}{l}
\hline Themes \\
Use of Student-centred Strategies \\
Immersion to Students' Diverse Cultural \\
Backgrounds
\end{tabular}

Backgrounds

Making the classroom into a class-home

Translation as strategy

Mastery of Basic Literacy Skills

\section{Core Ideas}

Pair work and cooperative techniques were conducted.

Apply small group activities

Fast and slow learning students were grouped together. Conduct grouping to let them feel they belong to the group and encourage to participate in the class.

Expose oneself to students' language orientation. Students must also accept the teacher's own culture. Use of home visitation to understand the struggles of the learners at home.

Foster a classroom free from discrimination.

Equal treatment to students

Listen to students' stories about their home

Translate English words into vernacular to ensure that the students understand the lesson.

Make a compendium of IP language term.

Ensure students' mastery to basic language concept Let the students understand first the concept using their vernacular

\section{Discussion}

The purpose of this phenomenological inquiry is to highlight the cultural responsive teaching practices of language teachers in Pong-Pong Elementary School, Davao de Oro. This also aimed to find out the different ways employed by the teachers to address cultural differences in language instruction.

\section{Experiences of language teachers in indigenous classrooms}

There are seven essential themes emerged from the analysis of data for the first research question.

\section{Use of code- switching in the discussion}

The first the essential theme generated from the response of the research participants. As it is revealed from the IDI an FGD conducted, Teaches have to translate the lesson from English to vernacular and even start teaching of the basic in English topics using the Vernacular of the students. Additionally, according to them, as they teach the language lesson, they have to utilize the list of vocabulary words in translating to facilitate understanding among IP students. 
Moreover, teachers also have to revise the content into Mandaya and ask assistance from other students who are competent both native language and the target language. Translation of the sentences in instruction and giving more examples are also practiced by non-IP teachers of English subjects.

Chou (2016) and Ciun (2016) also implicated that concurrent translation which includes meaning translation and literal translation or the use of code switching as strategies for teaching indigenous people. The purpose is to use the best of the first language in target language learning and to use the first language as a powerful recourse of target language learning (Ciun, 2016). They suggested that in order to deliver the lesson well to indigenous learners, teachers have to translate from English to the vernacular language of the IP students.

According to Bautista and Mulligan (2010 as cited by Cabal 2018), it is favorable on the part of the students to when teachers use the language which is familiar to the students during the delivery of the language lesson. When teachers explain the language concepts in language students can understand, the chance of grasping the concept becomes accessible and attains higher degree of mastery.

Seemingly, by using learners' home language, learners are more likely to engage in the learning process. This promotes interaction among students in the language class where they can make suggestions, ask questions, answer questions and create and communicate new knowledge with enthusiasm. It gives learners confidence and help them affirm their cultural identity. This in turn has positive impact on the way learners see the relevance of school to their lives (Lumby and McGloiun ,2009; Calderon, Slavina and Sanchez, 2011; Pennycock, 2010 as cited by Cabal 2018).

\section{Linguistic Contrast of Teachers' and Students' Native Language}

This is one of the essential themes that emerged from the responses of the research participants. NonIP English Teachers stated that IP students have difficulty in understanding the target language used in the classroom. Teachers also make major adjustment to the students" level of linguistic competence. This somehow hinders English teachers to deliver the lesson due to linguistic barrier. Difficulty in teaching pronunciation is also manifested in the language class.

Communication barriers in the classroom make it difficult for students to get the most out of their education. Similarly, consideration of students' culture as well as their first language at home is a need to be considered by teachers. Miller and Wilde (2013) stated that differences of the first language at home and language of instruction at school may be a disadvantage in the process of learning. Thus, these children often become alienated and feel disengaged from learning.

As supported by Isphording and Otten (2014), linguistic barrier or distance is an obstacle to the acquisition of a language, which leads to large differences in the attainments of the language skills necessary for social integration in the classroom.

\section{Challenges in the Implementation of the Curriculum}

Another theme that emerged from the participants' responses is the difficulty to deliver the lesson. As revealed from the interview, there is a difficulty among non-IP English teachers to follow the Curriculum Guide due to students' low-level of comprehension. Teachers confessed that they are not able to explain the lesson well and could not understand students' answers. This is consonance with Gao, (2011), Moyo, (2011) and Lee (2014) researched that English language teaching to indigenous students can be a frightful experience. It is assumed that teachers always have apprehensions and pressures upon teaching because they are not familiar with the cultural backgrounds of the students. 


\section{Lowering the Filter of Anxiety level}

Teachers in order to accommodate the learning gap in a language classroom, fosters a socially caring climate which allows learners to feel the sense of belongingness. In doing so, they mix the IP students to NonIP students in different activities conducted in the language class.

Classroom teachers must have a deep understanding of students' culture in order for them to maximize every learning opportunity. In the same manner, cultural knowledge represented in the classroom settings should be gained by teachers to design lesson and instructional activities that reflect how students communicate and learn.

As a whole, students learn about themselves and the world around them within the context of their own culture. Hence, it is important that teachers should consider this premise in designing the kind of instruction they are going to have in their classes (Blodgett, Schinke, Smith, Peltier and Pheasant, 2011; Kottak and Kozaitis, 2012; Cushner, McClelland, and Safford, 2012; Mcgloin, Colleen and Carlson, Bronwyn, 2013).

In a classroom setting wherein integration of students' culture is not observed, where teacher neglect the importance of students' culture in the different instructional activities, where teachers do not integrate sensitivity to students culture, students may not develop their fullest potentials as individuals. In most cases, these students may feel the pressure of understanding the lessons in which they might have hard time and forced themselves to dig into the concept of the lessons. This alienation will bring a negative impact to students' engagement in class activities and can be one reason for school failure (Bajaj, 2011; Gándara and Hopkins, 2010; Chilisa, 2014).

\section{Availability of language exercises in the target language}

One of the essential themes that also emerged upon analysis from the responses of the participants is the use drills as a strategy in language lesson. As shared by participants in in-depth interview, they provided practices sets and drills on the target language to acquire the target skills or attain the target learning outcomes. Moreover, they also make use of read aloud in class and explain the literary piece to the students.

As stated by Chinn (2007); Dentith and Maurer (2011); Bembenutty, 2011; and Cabal (2017), there is a big challenge for teachers to design culturally relevant pedagogical practices in teaching students from culturally and linguistically diverse backgrounds. This requires deep understanding of students' culture and applying special teaching techniques that is based on understanding of the role of culture in learning.

Harris and Duibhir (2013) reported that students benefit from practice because they are able to apply knowledge through interaction. Students connect with the material when they work with texts and concepts beyond a one-time exposure. When students practice using the knowledge through application, they connect with information on a deeper level.

\section{Themes and Core Ideas on How Language Teachers cope with the Challenges in Providing a Cultural Responsive Teaching in Indigenous Classrooms}

The research participants were asked about the challenges they encountered in teaching IP students and the ways they implemented to lessen the problem that they encountered in the classroom and the different strategies they found effective in handling IP learners in the process of proving a culturally sensitive curriculum.

\section{Use of Student-Centred Strategies}

This is one of the essential themes emerged from the responses given by the participants on the 
second research question. This theme was manifested when they affirmed that they apply interactive communication, conduct collaborative activities and apply small group activities at the same time mix the fast and slow learning students while implementing cooperative learning activities in the language class.

This is in consonance with the notion of many researches that cultural background of the students should always be the consideration of teachers in designing cooperative learning activities. It must be reflected by teachers that students from different cultures also learn in different ways. Some cultural groups prefer to learn in cooperation with others, while others prefer working in-dependently. Knowing this, varied learning needs of students must be addressed by teachers without neglecting the integration of students' culture in the instruction (Kidwell, 2011; Santoro, Reid, Crawford and Simpson, 2011; Wyman, 2012; cited in the work of Cabal 2017).

\section{Immersion to Students' Diverse Cultural Backgrounds}

Another theme that emerged from the responses of the research participants is by being positive and adaptive to students' diverse cultural backgrounds. As confessed by non-IP English teachers, there is a need to explore oneself to students' language orientation and accept the challenge positively and embrace the responsibility at work wide open in order to be effective. Moreover, they have to extend patience to their students and acknowledge that in doing so, students must also accept the teacher's own culture.

Cabal (2017) states that it is essential for teachers upon designing activities to know the cultural backgrounds of the students to make learning more meaningful and engaging. Alongside this, creating class activities becomes easier when the teachers have a a wide acceptance of the cultural back-ground of their students' perceptions on the value of school knowledge, their experiences with the different subject matters in their everyday settings, and their prior knowledge of and experience with specific topics in the curriculum, (Battiste, 2009; Lin and Ivinson, 2012; Chartrand, 2012 as cited by Cabal, 2017).

Inclusion of students' cultural references in all aspects of learning is of prime importance in providing a culturally responsive teaching. It is in this type of pedagogical practice that acknowledges, responds to, and celebrates fundamental cultures to assure that full and equitable access of education to students of differing ethnicity and social origins. In order to effectively attain meaningful learning experiences, many educators believed that teachers should practice culturally responsive pedagogical strategies (McCarty, Romero-Little and Warhol, 2009; Gay, 2010; Atalay, 2012 as cited by Cabal 2018).

In order to make every student learn, culture should always be a central factor to teaching and learning. When teachers consider culture an important aspect in language teaching, teachers are not just communicating and receiving information but also influencing how group of individual think (Reyhner and Singh, 2010; Cross-Townsend, 2011; Brayboy, Fann, Castagno, and Solyom, 2012 as cited by Cabal 2018).

\section{Translation as a Strategy}

This is also one of the essential themes identified from the answers provided by research participants. As stated by non-IP English teachers, it is evident as it is a necessity in their language class to translate English words to vernacular and even translate the lesson to the native language of the students.

Many studies suggested a positive and facilitative role of translation (Newmark (1991); Husain (1994); Kern (1994); Omura (1996) as cited by Mogahed (2013). Recent research in pragmatics also suggests that greater awareness of L1 helps in the more effective communicative use of L2. Translation is a means by which both languages can be assessed. Rather than being seen as an obstacle to real language use, translation might more effectively be viewed as a way of fine-tuning the language to be used in given situations and conditions (Owen, 2003; Mogahed 2013).

Liao (2006) as cited by Mogahed (2013) summarizes the positive aspects of using translation: (1) it can help students comprehend L2; (2) it can help students to check whether their comprehension is correct; 
(3) it eases memory constraints in memorizing more words, idioms, grammar, and sentence structures; (4) it can help students develop and express ideas in another language; and (5) it can help reduce learning anxiety and enhance motivation to learn L2.

\section{Mastery of Basic Literacy Skills}

This theme is also manifested when teachers also emphasized that in teaching language items or lessons, they have to ensure that IP students should acquire first the basic mastery of basic literacy skills. Upon delivery of the language concepts, they have to ensure that students must have mastery with basic language concept as this is essential for the acquisition of more complicated language skills.

Additionally, let the students understand first on their own language and ensure that students also have mastery over other languages.

Harris and Duibhir (2013) stated that the development of students' L2 literacy skills supports the development of their second language proficiency in general. Reading aloud (teacher reading aloud to children) is a useful strategy to model correct pronunciation, stress and intonation and to help the children develop comprehension skills by focusing on units of meaning, especially in the beginning stages of language learning.

Research findings recommend introducing L2 learners to literacy in a gradual way from the early stages of language learning, taking account of the wider literacy instruction in other languages in the school and L1 literacy in particular. L2 reading strategies need to be explicitly taught.

\section{Conclusions}

Indigenous classroom is indeed an interesting topic to explore in education. Teachers strive to provide a contextualized education which makes connections of students' reality and the curriculum.

The researcher recognized that what has been provided in this phenomenological inquiry is just a bit of information in the spectrum of indigenous language education. There is so much to study and investigate in order to shed light on the different effective practices of teachers to make the classroom learning experiences culturally relevant on student's home backgrounds. As this study investigated the cultural responsive teaching practices of language teachers in an indigenous classroom, it is also acknowledged that the findings may at some extent different to other lived experiences of teachers handling IP learners. This study lacks the level of generalization which empirical researches wish to find. Moreover, micro-scaled studies are also essential to provide a thick description of teachers' experiences inside the indigenous classroom.

Lastly, it is recognized that there can be a lot of ways to study the cultural responsive teaching not only on the lived and shared experience of language teachers but on the other side of the spectrum-the experiences of IP students. Aside from the geographical location, participants and experiences of teachers in providing a cultural responsive teaching, it is also I believed there can be better opportunities for further research in order to shed light on the many issues and challenges related to cultural responsive teaching. 


\section{References}

Abebe, T. T., \& Davidson, L. M. (2012). Assessing the role of visual teaching materials in teaching English vocabulary (Report). Language In India, 12(3), 524.

Battiste, M. (2009). Naturalizing indigenous knowledge in Eurocentric education. Canadian Journal of Native Education, 32(1), 5.

Bautista, D., \& Mulligan, J. (2010). Solutions of addition and subtraction word problems by Filipino public school children. Manuscript submitted for publication.

Bembenutty, H. (2011). Self-regulated learning: New directions for teaching and learning. Hoboken: John Wiley \& Sons.

Blodgett, A. T., Schinke, R. J., Smith, B., Peltier, D., \& Pheasant, C. (2011) In Indigenous words: Exploring vignettes as a narrative strategy for presenting the research voices of Aboriginal com-munity members. Qualitative Inquiry, 17(6), 522-533.

Brayboy, B. M. J., \& Castagno, A. E. (2009). Self- determination through selfeducation: Culturally responsive school for Indigenous students in the USA. Teaching Education, 20(1), 31-53.

Brayboy, B. M. J., Fann, A. J., Castagno, A. E., \& Solyom, J. A. (2012). Postsecondary education for American Indian and Alaska Natives: Higher education for nation building and self- determination. ASHE Higher Education Report, 37(5).

Brewer J. and Hunter A. (1989). Multimethod research: a synthesis of styles, Newbury Park: Sage, Sage Library of Social Research Series, Vol. 175

Busch, D. (2010). Pre-service teacher beliefs about language learning: The second language acquisi-tion course as an agent for change. Language Teaching Research, 14(3), 318- 337.

Cabal, J.H. (2017). Lived - Experiences of English Teachers Of Talaingod Students : Pedagogical Challenges in Focus.International Journal of Advancements in Research \& Technology, Volume 7, Issue 8, August 201824 ISSN 2278-7763

Cao, D. C. (2012). A Theoretical Framework for China's Business English Based on International Business Communication. Foreign Language in China, 9(3), 10-15.

Causey, V. E., Thomas, C. D., \& Armento, B. J. (2000). Cultural Diversity Is Basically a Foreign Term to Me: The Challenges of Diversity For Preservice Teacher Education. Teaching And Teacher Education, 16 (1), 33-45.

Chew, K. A. B. (2015). Family at the heart of Chickasaw language reclamation. American Indian Quarterly, 39(2), 154-179.

Chilisa, B. (2014). Mixed methods in Indigenous research: Building relationships for sustainable inter vention outcomes. Journal of Mixed Methods Research, 8(3), 222-233. Retrieved from http://dx.doi.org/10.1177/1558689814527878 
Chilisa, B., \& Preece, J. (2005). African perspective in adult learning: research methods for adult educators. Hamburg, German: UNESCO Institute of Education.

Chinn, P. W. U. (2007). Decolonizing methodologies and indigenous knowledge: The role of culture, place and personal experience in professional development. Journal of Research in Science Teaching, 44, 1247-1268. Retrieved from http://dx.doi.org/10.1002/tea.20192

Cross-Townsend, M. (2011). Indigenous Education and Indigenous Studies in the Australian Acade-my', in G. J. S. Dei (ed.), Indigenous Philosophies and Critical Education, N.Y.: Peter Lang Publishing Inc.

Creswell, J.W.(2007). Qualitative inquiry \& research design: Choosing among five approaches (2nd ed.). Thousand Oaks, CA: Sage.

Dentith, A., \& Maurer, A. (2011). Interdisciplinary paths to cultural competencies and global aware-ness: The San Antonio Project. MakingConnections: Interdisciplinary Approaches to Cultural Diversity, 12(2), 52-64.

Edwards, S. (2011). Developing diversity dispositions for White culturally responsive teachers. Action in Teacher Education, 33 (5/6), 493-508.

Fujii, Y. (2012). Raising awareness of interactional practices in L2 conversations: Insights from conversation analysis. International Journal of Language Studies, 6(3), 99-126.

Gándara, P., \& Rumberger, R. W. (2009). Immigration, language, and education: How does language policy structure opportunity? Teachers College Record, 111(3), 750-782.

Gándara, P., \& Hopkins, M. (Eds.). (2010). Forbidden language: English learners and restrictive language policies. New York, NY: Teachers College Press

Gay, G. (2000). Culturally Responsive Teaching: Theory, Research, and Practice. New York: Teachers College Press.

Gay, G. (2010). Culturally responsive teaching: Theory, research, \& practice (2nd ed.). New York: Teachers College Press.

Glas, K. (2013). Teaching English in Chile. A study of teacher perceptions of their professional identi-ty, student motivation and pertinent learning contents. Frankfurt, Germany: Peter Lang.

Grant, C. A., \& Tate, W. E. (1995). Multicultural education through the lens of the multicultural education research literature, In J. A. Banks \& C.A.M. Banks (Eds.), Handbook of research on multicultural education (pp. 145-166). New York, NY: MacMillan. 
Guba, E.G. (1981) Criteria for assessing the trustworthiness of naturalistic inquiries, Educational Communication and Technology Journal 29(1981), 75-91.

Hung, D., Lee, S. S., \& Lim, K. Y. (2012). Teachers as brokers: Bridging formal and informal learning in the 21st century. KEDI Journal of Educational Policy, 9(1).

Kidwell, C. (2011). American Indian studies as an academic discipline. American Indian Culture and Research Journal, 35(1), 27-31.

Kirkpatrick, R., \& Ghaemi, H. (2011). Beyond the communicative approach in language teaching. Modern Journal of Language Teaching Methods, 1(3),

Ladson-Billings, G. (2004). New directions in multicultural education: Complexities, boundaries, and critical race theory. In J. A. Banks \& C.A.M. Banks (Eds.), Handbook of research on multicultural education (2nd ed., pp. 50-65). San Francisco: John Wiley \& Sons, Inc.

Lee, T. (2009). Language, identity, and power: Navajo and Pueblo young adults' perspectives and experiences with competing language ideologies.Journal of Language, Identity, and Education, 8(5), 307-320. Retrieved from http://dx.doi.org/10.1080/15348450903305106

Lee, T. (2014). Critical language awareness among Native youth in New Mexico. In $\quad$ L. T. Wyman, T. L. McCarty, \& S. E. Nicholas. (Eds.), Indigenous youth and multilingualism: Language identity, ideology, and practice in dynamic cultural worlds (pp. 130148). New York: Routledge.

Lincoln, Y.S., (1995).Emerging criteria for quality in qualitative and interpretive research, Qualitative Inquiry 1 (1995), 275-289.

Lincoln, Y. S., \& Guba, E. G. (2000). Paradigmatic controversies, contradictions, and emerging confluences. In N. K. Denzin \& Y. S. Lincoln (Eds.), The handbook of qualitative research (2nd ed., pp. 163- 188).Beverly Hills, CA: Sage.

McCarty, T. L., Romero-Little, E., \& Warhol, L. (2009). Indigenous youth as language policy makers. Journal of Language, Identity, and Education, 8, 291- 306. Retrieved http://dx.doi.org/10.1080/15348450903305098

Marx, H. A. (2008). Please mind the gap: A pre-service teacher's intercultural development during a study abroad program. Unpublished

Dissertation: University of Connecticut.

Meek, B. A. (2011). Failing American Indian languages. American Indian Culture and Research Journal, 35(2), 43-60

Merriam, S.B. (1998). Qualitative research and case study applications in education, San Francisco: Jossey-Bass

Moyo, T. (2011). Unequal official languages: the case of South Africa's official languages. Faculty of Arts 5th Annual Conference (pp. 74-83). KwaDlangezwa: University of Zululand. 
Nakata, M., Nakata, V., Keech, S., \& Bolt, R. (2012). Decolonial goals and pedagogies for Indigenous studies. Decolonization: Indigeneity, Education \& Society, 1(1).

Nhan, N. T., \& Lai, H. T. (2012). The enhancement of learner autonomy and the growth of English language proficiency (Report). Language in India, 12(4), 427.

Patton, M. Q. (2002). Qualitative research and evaluation methods (3 ${ }^{\text {rd }}$ ed.) Thousand Oaks, CA: Sage.

Pitts J.M. (1994). Personal understandings and mental models of information: a qualitative study of factors associated with the information- seeking and use of adolescents, PhD Thesis, Florida StateUniversity

Reyhner, J. (2010). Indigenous language immersion schools for strong Indigenous identities. Heritage Language Journal, 7(2), 138-152.

Reyhner, J., \& Singh, N. K. (2010). Cultural genocide in Australia, Canada, New Zealand, and the United States: The destruction and transformation of indigenous cultures. Indigenous Policy Journal, 21(4)

Saifer, S., Edwards, K., Ellis, D., Ko, L., \& Stuczynski, A. (2011). Culturally responsive standards-based teaching: Classroom to community and back (2nd ed.). Thousand Oaks, CA: Education Northwest and Corwin Press.

Santoro, N., Reid, J., Crawford, L., \& Simpson, L. (2011). Teaching Indigenous children: Listening to and learning from Indigenous teachers. Australian Journal of Teacher Education, 36(10), 65-76.

Silverman, D., (2001). Interpreting qualitative data: methods for analysing talk, text and interaction, $2^{\text {nd }}$ ed. London: Sage

Silverman, D. (1998). Harvey Sacks: Social science and conversation analysis. New York: Oxford University.

Sleeter, C. E., \& Owuor, J. (2011). Research on the impact of teacher preparation to teach diverse students: The research we have and the research we need. Action in Teacher Education, 33(5/6), 524-536.

Sun, D. (2014).From communicative competence to interactional competence: A New Outlook to the Teaching of Spoken English. Journal of Language Teaching and Research, 5(5), 10621070 .

Tatum, A. (2000). Breaking down the barriers that disenfranchise African in low level tracks. Journal of Adolescent and Adult Literacy,

Van Maanen, M. (2007). Phenomenology of practice. Phenomenology \&

Vavrus, M. (2002). Transforming the multicultural education of teachers: practice. New York: Teachers College Press.
American adolescent readers 44(1), 52-64.

Practice, $\quad 1(1)$.

Theory, research and 
Zeichner, K. M. (1993). Educating teachers for cultural diversity. East on Lansing, MI: Michigan State University, National Center for

Research Teacher Learning 